carried out with extensive measurements involving workers of specific sectors (fishing, farming, quarry).

Conclusion The developed algorithm is an instrument useful for determining the cumulative UV erythemal dose of workers with the best possible level of approximation, since it was obtained on the basis of the previous working exposure derived from a questionnaire filled by the worker itself. The algorithm can be also used as prevention instrument for the previous evaluation of the occupational risk.

\section{SURGICAL SMOKE - WHAT IS IT AND WHAT ARE THE RISKS? A REVIEW}

S Addley*, D Quinn. Antrim Area Hospital, UK

\subsection{6/oemed-2018-ICOHabstracts.918}

Introduction Operating room (OR) staff are exposed to surgical smoke on a daily basis. With the increased use of intraoperative smoke-generating devices, this is a significant occupational health hazard.

Methods A database search was performed for literature on surgical smoke from 1980-2017.

Results Electro-, laser and ultrasonic surgical techniques produce surgical smoke. $95 \%$ of surgical smoke is water and $5 \%$ is a combination of chemicals and cellular debris. Up to eighty chemicals, including the carcinogen Benzene, have been identified. The chemical load from cautery of one gram of tissue is comparable to that derived from six cigarettes. HIV and HPV viral DNA have been isolated, and both Staphylococcus and Neisseria cultured from surgical smoke. At less than ten micrometres in diameter, surgical smoke particles can remain airborne and are inhalable; the smallest fractions entering the alveoli. Smoke particles diffuse along concentration gradients within the OR atmosphere exposing all staff, and not just the operator or those scrubbed. Animal studies have demonstrated pulmonary congestion, interstitial pneumonia and emphysema secondary to surgical smoke exposure. Associated symptoms reported by staff include headache, problematic lacrimation and cough - affecting 58\%, $42 \%$ and $20 \%$ of doctors respectively in one survey. An association with cancer has been made through case series. Standard surgical facemasks offer no protection; whilst portable evacuation devices are the best risk reduction measure. No legislation currently exists in the United Kingdom, but many international organisations offer guidance on minimising surgical smoke exposure in the workplace.

Conclusion OR staff training ad policies should align with the latest guidance so that appropriate risk reduction measures can be put in place to protect health.

\section{PREVALENCE OF PRESENTEEISM AND ITS ASSOCIATED FACTORS AMONG NURSES IN A TEACHING HOSPITAL IN NIGERIA}

Antoinette N Ofili*, Ederhion J Obehi, Edeh S Chibuike, Edo E Ose. Department of Community Health, School of Medicine, University of Benin, Benin City, Nigeria

\subsection{6/oemed-2018-ICOHabstracts.919}

Introduction Presenteeism is defined as going to work despite having medical conditions that suggest one should be absent. There is dearth of studies on presenteeism among nurses globally, especially in Africa, and Nigeria inclusive. This study therefore assessed the prevalence of presenteeism and its associated factors among nurses at a teaching hospital in Nigeria.

Methods A Cross-sectional study was carried out among nurses (317) at the University of Benin Teaching Hospital, Nigeria (August 2015 to July 2016). Inclusion criteria were nurses, who had worked in direct assistance to patients, gave their consent and had spent at least one year in the service of the hospital. Stratified random sampling technique was utilised. Pre-tested, self-administered questionnaire was used for data collection. Minimum Sample size calculated was 317. Data was analysed using IBM SPSS Version 21.0. Ethical approval was gotten and confidentiality was ensured during the study.

Results The response rate was $100 \%$ and the mean age of the respondents was $41.9 \pm 9.2$ years. In the last 12 months, 242 $(76.3 \%)$ respondents had reported to work sick and out of these $77(31.8 \%)$ had reported twice, 48 (19.8\%) had reported seven times while $32(13.2 \%)$ had reported thrice. Several reasons were given for going to work sick. Age, marital status, years worked in the hospital, nursing cadre, highest level of qualification and level of job satisfaction were found to be associated with presenteeism $(\mathrm{p}<0.05)$.

Discussion The high prevalence of presenteeism in this study could be attributed to high level of job satisfaction and heavier workload after a sick leave. Among the respondents that had reported to work sick in the last 12 months, malaria was the commonest condition. Nigeria is a malaria endemic region. It is recommended that the management of the hospital pay closer attention to the consequences of nurses' presenteeism.

\section{EVALUATION OF THE OCCUPATIONAL BIOLOGICAL RISK AT THE HEMODIALYSIS CENTRES OF CASABLANCA}

S Touil* ${ }^{*}$ I El Amri, B Benali, M Jarmoune, A El Kholti. Casablanca Faculty of Medicine and Pharmacy, Hassan II University, Morocco

\subsection{6/oemed-2018-ICOHabstracts.920}

Introduction accidental blood exposures (ABE) are common in everyday practice. On a daily basis, they represent an indisputable risk for various categories of medical occupations. In hemodialysis, the risk of $\mathrm{ABE}$ is omnipresent for health care professionals.

Methods This is a study carried out amongst the staff of hemodialysis centres in the public health sector of the city of Casablanca using a questionnaire containing four sections: general information, $\mathrm{ABE}$ risk assessment, conduct in case of $\mathrm{ABE}$ and prevention evaluation.

Results One hundred people responded to the questionnaire, with 52 physicians and 48 paramedics. The most common acts were the pose of catheters, followed by venous sampling and the attachment of infusions. Respectively, 65\% and $61 \%$ of the respondents brought up the concept of recapping and manual mismatching of needles. Thirty two doctors and 32 nurses were victims of $\mathrm{ABE}, 59$ were puncture cases and 22 were projection accidents. Twenty-eight of them were in an emergency situation and 23 were in front of a patient who was difficult to prick. Thirty participants had received training on ABE.

Discussion in a French epidemiological study, they found that $70.2 \%$ of the $\mathrm{ABE}$ in dialysis were punctures, which matches our results (70\%). They also found that $63 \%$ of $\mathrm{ABE}$ were preventable only by respecting standard precautions and 